\title{
An Investigation of the Use of Traditional Chinese Medicine in Stroke Patients in Taiwan
}

\author{
Chien-Chang Liao, ${ }^{1,2}$ Jaung-Geng Lin, ${ }^{3}$ Chin-Chuan Tsai, ${ }^{4}$ Hsin-Long Lane, ${ }^{4}$ Ta-Chen Su, ${ }^{5}$ \\ Hwang-Huei Wang, ${ }^{6}$ Fung-Chang Sung, ${ }^{2,7}$ Ta-Liang Chen, ${ }^{1}$ and Chun-Chuan Shih ${ }^{4,8}$
}

${ }^{1}$ Department of Anesthesiology, Taipei Medical University Hospital, Taipei 110, Taiwan

${ }^{2}$ Management Office for Health Data, China Medical University Hospital, Taichung 404, Taiwan

${ }^{3}$ Graduate Institute of Chinese Medicine, China Medical University, Taichung 404, Taiwan

${ }^{4}$ School of Chinese Medicine for Post-Baccalaureate, I-Shou University, Kaohsiung City 84001, Taiwan

${ }^{5}$ Department of Cardiology, National Taiwan University Hospital, Taipei 100, Taiwan

${ }^{6}$ Graduate Institute of Integrated Medicine, College of Chinese Medicine, China Medical University, Taichung 404, Taiwan

${ }^{7}$ Department of Public Health, China Medical University, Taichung 404, Taiwan

${ }^{8}$ Chinese Medical Association, Taipei 100, Taiwan

Correspondence should be addressed to Chun-Chuan Shih, hwathai@seed.net.tw

Received 11 September 2012; Revised 14 November 2012; Accepted 19 November 2012

Academic Editor: Alvin J. Beitz

Copyright ( $) 2012$ Chien-Chang Liao et al. This is an open access article distributed under the Creative Commons Attribution License, which permits unrestricted use, distribution, and reproduction in any medium, provided the original work is properly cited.

\begin{abstract}
Background. The use of complementary and alternative medicine in critical illness is increasing worldwide. This study investigates how traditional Chinese medicine (TCM) is used in stroke patients. Methods. Using Taiwan National Health Insurance reimbursement claims, we compared the annual use of TCM between stroke patients and general population, identifying 15,330 patients with a new onset of stroke in 2000-2009. The sociodemographic status and medical comorbidities between stroke patients receiving TCM services and those without using the service were compared. Results. The use of TCM was higher in stroke patients than in the general population, $27.9 \%$ versus $25.4 \%$ in 2000 and $32.7 \%$ versus $27.8 \%$ in 2009 , respectively, and grew consistently from 2000 to 2009. Among stroke patients, women, younger patients, white-collar employees, higher-income residents, and those living in areas with more TCM physicians were more likely to use TCM. Stroke patients using rehabilitation services were more likely to have more TCM visits $(\mathrm{OR}=2.28,95 \% \mathrm{CI}=1.96-2.66)$ and higher expenditure on $\mathrm{TCM}(\mathrm{OR}=2.67,95 \% \mathrm{CI}=2.29-3.12)$ compared with stroke patients without rehabilitation. Conclusion. TCM is popular and well accepted in Taiwan. Patients with stroke have a higher TCM utilization rate than people without stroke.
\end{abstract}

\section{Introduction}

Although the incidence of stroke is declining worldwide [1], it remains the leading cause of acquired disability in adults and the second leading cause of death in most areas $[2,3]$. Risk factors, prevention strategy, and genetic biomarkers of stroke have been well studied [3-5]. Stroke patients commonly suffer from sequelae and complications such as dementia, depression, pneumonia, urinary tract infection, decubitus, fall (hip fracture), epilepsy, dysphagia, and constipation [6,7]. Rehabilitation such as physical therapy may prevent sequelae after stroke or improve functional status [8]. Increasing numbers of stroke patients have sought alternative complementary and alternative medicine (CAM) or therapy to improve physical functions in recent years that is worthy of our attention [9-12].

Traditional Chinese medicine (TCM) is widely used in Taiwan [13-16] and other Asian countries [17-20]. Previous studies found that $10.4 \%, 28.4 \%$, and $62.5 \%$ of the general population have used TCM services in the previous month, year, and six years in Taiwan, respectively $[13,16,21]$. After stroke chronic symptoms such as spasticity, changed muscle tone, motor neuron excitability, and ankle plantar flexor spasticity can improve after TCM treatment, particularly acupuncture [22-26]. Our previous studies also proved the medical effectiveness of acupuncture [27, 28]. 
To our knowledge, this is the first population-based study of characteristics of TCM use in stroke patients. This study used medical claims from Taiwan's National Health Insurance Research Database to evaluate patterns of TCM use in stroke patients.

\section{Methods}

2.1. Study Design and Sample. Taiwan's National Health Research Institutes has documented all the medical claims for insured beneficiaries since 1996 as the National Health Insurance Research Database for public access. With patient identification numbers scrambled, data files can be secured to protect patient privacy. Information available for this study included gender, birthday, disease codes, health care rendered, medicines prescribed, diagnoses for admissions and discharges, and medical institutions and physicians providing services. From a longitudinal cohort data set of a randomly selected one million insured subjects, we identified patients aged $\geq 20$ years old with newly diagnosed stroke who were hospitalized in 2000-2009 as our eligible study subjects. In order to confirm that all stroke patients in our study were incident cases, only new-onset stroke cases were included in this study. The diagnosis of stroke was validated in previous studies [29]. Overall, 15,330 new-onset stroke patients were included in this study and followed to analyze their TCM use for one year. The outcome of this study is the rate of TCM use for people with the diagnosis of stroke in the first year. This study compared sociodemographic factors, coexisting medical conditions, and the characteristics of stroke between stroke patients with and without TCM use. The objective of this study is to investigate factors associated with the firstyear use of TCM for people suffering from stroke.

2.2. Criteria and Definition. We defined stroke according to the International Code of Diseases, Ninth Edition, Clinical Modification (ICD-9-CM 430-438). Coexisting medical conditions included hypertension (ICD-9-CM 401405), diabetes (ICD-9-CM 250), hyperlipidemia (ICD-9CM 272.0-272.4), and myocardial infarction (ICD-9-CM 410 and 412). From individuals' health reimbursement claims, regular renal dialysis (including hemodialysis and/or peritoneal dialysis) was also considered a medical condition among stroke patients in this study. We classified the frequency of visits for TCM into quartiles. Stroke patients in the highest quartile of TCM visits were defined as high TCM users. Medical expenditure on TCM was also classified into quartiles. Stroke patients who had the highest quartile of TCM expenditure were considered high TCM expenditure patients.

As Taiwan has 359 townships and city districts, we calculated the population density (persons $/ \mathrm{km}^{2}$ ) for each of these administrative units. Based on population density, these units were stratified into tertiles to designate areas of low, moderate, and high urbanization [14-16]. We calculated the density of TCM physicians (TCM physicians/10,000 persons) by using the number of TCM physicians per 10,000 residents for each of the administrative units. The first, second, and third tertiles were considered as areas with low, moderate, and high physician density, respectively $[14,16]$.

2.3. Statistical Analysis. The proportions of stroke patients using TCM services were calculated annually from 20002009 and compared with patients without stroke to observe trends in TCM use. Patients with stroke were further divided into two groups, those who did and did not use TCM. The sociodemographic status and comorbidities between these two groups were compared and examined using chi-square tests and analysis of variance. Univariate and multivariate logistic regression analyses were performed to calculate crude and adjusted odds ratios (ORs) and 95\% confidence intervals (CIs) measuring relationships between TCM use and associated factors for stroke patients. These factors included age, sex, occupation, low-income status, urbanization, density of TCM physicians in area, history of diseases, use of rehabilitation, types of stroke, and in-hospital characteristics. All analyses were performed using Statistical Analysis Software version 9.1 (SAS Institute Inc., Cary, North Carolina, USA). A two-sided probability value of $<0.05$ was considered significant.

2.4. Ethical Approval. This study was conducted in accordance with the Helsinki Declaration. To protect personal privacy, the electronic database was decoded for research with patient identification scrambled. According to National Health Research Institutes regulations, informed consent is not required because patient identification has been decoded. This study was evaluated and approved by Taiwan's National Health Research Institutes.

\section{Results}

The prevalence of TCM use among stroke patients increased from $24 \%$ in 2000 to $32 \%$ in $2009(P<0.0001)$ (Figure 1$)$. TCM use was higher in stroke patients than in general population annually from $2000-2009(P<0.0001)$ (Table 1$)$. Compared with nonusers, higher proportions of TCM users were females $(43.6 \%$ versus $41.3 \%, P=0.007)$, younger patients $(36.8 \%$ versus $26.6 \%, P<0.0001)$, white-collar employees $(38.7 \%$ versus $31.9 \%, P<0.0001)$, residents living in highly urbanized areas $(59.4 \%$ versus $54.6 \%, P<$ $0.0001)$, and areas with more TCM physicians $(28.3 \%$ versus $23.7 \%, P<0.0001)$. Low-income stroke patients were less likely to be TCM users $(0.7 \%$ versus $1.2 \%, P=0.004)$. TCM users were more likely to use other rehabilitation services than non-TCM users $(43.9 \%$ versus $28.1 \%, P<$ 0.0001). TCM users also experienced more comorbidities with hypertension $(64.4 \%$ versus $59.8 \%, P<0.0001)$ and hyperlipidemia $(12.2 \%$ versus $9.2 \%, P<0.0001)$ but less renal dialysis $(0.8 \%$ versus $2.1 \%, P<0.0001)$.

The multivariate logistic regression analysis showed ORs of factors associated with higher TCM uses in stroke patients (Table 2), including women $(\mathrm{OR}=1.16,95 \% \mathrm{CI}$ $=1.08-1.25)$, younger patients $(\mathrm{OR}=3.35,95 \% \mathrm{CI}=$ 2.36-4.76), white-collar employees $(\mathrm{OR}=1.38,95 \% \mathrm{CI}$ $=1.22-1.55)$, people without low income $(\mathrm{OR}=1.55$, $95 \% \mathrm{CI}=1.04-2.32$ ), areas with more TCM physicians 
TABle 1: Comparisons of sociodemographic characteristics, comorbidities, and other medical conditions between stroke patients using traditional Chinese medicine or not.

\begin{tabular}{|c|c|c|c|c|c|}
\hline \multirow[b]{3}{*}{ Sex } & \multicolumn{4}{|c|}{ TCM use } & \multirow{3}{*}{$\begin{array}{r}P \text { value } \\
0.007\end{array}$} \\
\hline & \multicolumn{2}{|c|}{ No $(N=10605)$} & \multicolumn{2}{|c|}{ Yes $(N=4725)$} & \\
\hline & $n$ & $(\%)$ & $n$ & $(\%)$ & \\
\hline Women & 4376 & $(41.3)$ & 2059 & $(43.6)$ & \\
\hline Men & 6229 & $(58.7)$ & 2666 & $(56.4)$ & \\
\hline Age, years & & & & & $<0.0001$ \\
\hline $20-29$ & 73 & $(0.7)$ & 65 & $(1.4)$ & \\
\hline $30-59$ & 2746 & $(25.9)$ & 1675 & $(35.4)$ & \\
\hline $60-69$ & 2514 & $(23.7)$ & 1309 & $(27.7)$ & \\
\hline$\geq 70$ & 5272 & $(49.7)$ & 1676 & $(35.5)$ & \\
\hline Mean \pm SD & \multicolumn{2}{|c|}{$68.0 \pm 13.3$} & \multicolumn{2}{|c|}{$63.7 \pm 13.1$} & $<0.0001$ \\
\hline Occupation, white collar & 3382 & $(31.9)$ & 1828 & $(38.7)$ & $<0.0001$ \\
\hline Low income & 126 & $(1.2)$ & 32 & $(0.7)$ & 0.004 \\
\hline \multicolumn{5}{|l|}{ Urbanization } & $<0.0001$ \\
\hline Low & 754 & $(7.1)$ & 270 & $(5.7)$ & \\
\hline Moderate & 4063 & $(38.3)$ & 1648 & $(34.9)$ & \\
\hline High & 5788 & $(54.6)$ & 2807 & $(59.4)$ & \\
\hline \multicolumn{3}{|l|}{ Density of TCM physicians } & & & $<0.0001$ \\
\hline Low & 2838 & $(26.8)$ & 1031 & $(21.8)$ & \\
\hline Moderate & 5256 & $(49.6)$ & 2358 & $(49.9)$ & \\
\hline High & 2511 & $(23.7)$ & 1336 & $(28.3)$ & \\
\hline Rehabilitation & 2982 & $(28.1)$ & 2072 & $(43.9)$ & $<0.0001$ \\
\hline Hypertension & 6343 & $(59.8)$ & 3044 & $(64.4)$ & $<0.0001$ \\
\hline Diabetes mellitus & 3102 & $(29.3)$ & 1385 & $(29.3)$ & 0.94 \\
\hline Hyperlipidemia & 972 & $(9.2)$ & 578 & $(12.2)$ & $<0.0001$ \\
\hline Myocardial infarction & 241 & $(2.3)$ & 98 & $(2.1)$ & 0.44 \\
\hline Renal dialysis & 220 & $(2.1)$ & 39 & $(0.8)$ & $<0.0001$ \\
\hline Ischemic stroke & 6481 & $(61.1)$ & 2839 & $(60.1)$ & 0.29 \\
\hline Length of stay, $<10$ day & 6797 & $(64.1)$ & 3054 & $(64.6)$ & 0.52 \\
\hline Mean \pm SD & \multicolumn{2}{|c|}{$11.8 \pm 18.9$} & \multicolumn{2}{|c|}{$11.8 \pm 14.8$} & 0.93 \\
\hline
\end{tabular}

SD: standard deviation; TCM: traditional Chinese medicine.

$(\mathrm{OR}=1.34,95 \% \mathrm{CI}=1.20-1.49)$, use of other types of rehabilitation $(\mathrm{OR}=2.15,95 \% \mathrm{CI}=1.99-2.32)$, and patients with comorbidities of hypertension $(\mathrm{OR}=1.29$, $95 \% \mathrm{CI}=1.20-1.39)$ and hyperlipidemia $(\mathrm{OR}=1.29$, $95 \% \mathrm{CI}=1.15-1.44)$ and without renal dialysis $(\mathrm{OR}=2.79$, $95 \%$ CI $=1.97-3.95)$. Shorter hospitalization was a factor associated with TCM use $(\mathrm{OR}=1.14,95 \% \mathrm{CI}=1.05-$ 1.24).

The average of TCM visits in stroke patients was higher in young adults than in older people $(9.8 \pm 16.4$ versus $7.8 \pm 10.6, P=0.0009)$. Stroke patients who were whitecollar employees, who lived in highly urbanized areas and areas with more TCM physicians, or who used rehabilitation services made more TCM visits (Table 3 ). Patients who had more visits for TCM care also had higher expenditure for TCM use.

\section{Discussion}

This study compared trends in TCM use by patients with stroke and general population to investigate clinical factors associated with TCM use in stroke patients. TCM use was consistently higher among stroke patients than in general patients from 2000 to 2009. TCM use in patients with stroke is highly correlated with sociodemographic characteristics.

These data challenge the biomedical profession's previous assumption that the biomedical system defines our society's health care practices. To the best of our knowledge, 
TABLE 2: Factors associated with use of traditional Chinese medicine among stroke patients in multivariate logistic regression model.

\begin{tabular}{|c|c|c|}
\hline & Number & $\begin{array}{c}\text { TCM use* } \\
\text { Adjusted OR (95\% CI) }\end{array}$ \\
\hline \multicolumn{3}{|l|}{ Sex } \\
\hline Women & 6435 & $1.16(1.08-1.25)$ \\
\hline Men & 8895 & 1.00 (reference) \\
\hline \multicolumn{3}{|l|}{ Age, years } \\
\hline $20-29$ & 138 & $3.35(2.36-4.76)$ \\
\hline $30-59$ & 4421 & $1.94(1.77-2.12)$ \\
\hline $60-69$ & 3823 & $1.60(1.46-1.75)$ \\
\hline$\geq 70$ & 6948 & 1.00 (reference) \\
\hline \multicolumn{3}{|l|}{ Occupation } \\
\hline White collar & 5210 & $1.38(1.22-1.55)$ \\
\hline Blue collar & 7763 & $1.21(1.08-1.36)$ \\
\hline Others & 2357 & 1.00 (reference) \\
\hline \multicolumn{3}{|l|}{ Urbanization } \\
\hline Low & 1024 & 1.00 (reference) \\
\hline Moderate & 5711 & $1.04(0.89-1.22)$ \\
\hline High & 8595 & $1.09(0.93-1.29)$ \\
\hline \multicolumn{3}{|l|}{ Density of TCM physicians } \\
\hline Low & 3869 & 1.00 (reference) \\
\hline Moderate & 7614 & $1.12(1.01-1.24)$ \\
\hline High & 3847 & $1.34(1.20-1.49)$ \\
\hline Without low-income status & 15172 & $1.55(1.04-2.32)$ \\
\hline Used rehabilitation therapy & 5054 & $2.15(1.99-2.32)$ \\
\hline Without diabetes mellitus & 10843 & $1.02(0.94-1.10)$ \\
\hline Hypertension & 9387 & $1.29(1.20-1.39)$ \\
\hline Hyperlipidemia & 1550 & $1.29(1.15-1.44)$ \\
\hline Without myocardial infarction & 14991 & $1.03(0.81-1.32)$ \\
\hline Without renal dialysis & 15071 & $2.79(1.97-3.95)$ \\
\hline Length of stay, $<10$ days & 9851 & $1.14(1.05-1.24)$ \\
\hline
\end{tabular}

OR: odds ratio; CI: confidence interval; TCM: traditional Chinese medicine.

*Hosmer-Lemeshow goodness of fit, $P=0.16$; c-statistic $=0.65$.

our study is the first population-based study to analyze the use of TCM and to study its association with stroke patients.

The increasing use of CAM [9-11,30] or TCM [1320, 30-33] has been reported in both Asian and Western countries. Consistent with previous reports indicating increased use of TCM in general populations [13-16], the present study found that the prevalence of TCM use in stroke patients increased from $24 \%$ in 2000 to $32 \%$ in 2009 . TCM is considered a subdivision of CAM in Western countries, with acupuncture treatment increasingly used in Western societies $[34,35]$, particularly for stroke patients [22, 23, 25, 36-42]. Evidence-based studies have shown TCM's beneficial effects in addressing physical and mental illnesses in stroke patients [22-26, 36-38].

Demographic factors such as age and sex are associated with patient choice of TCM $[13,14,16,18,19,21,31]$. Young and middle-aged adults were more likely than older people to use TCM; this trend also extends to foreign whitecollar workers in Taiwan [42]. Many studies demonstrate that TCM herbal medicine is helpful in maintaining regular menstruation [43]; this may help to explain why females were more likely to adopt TCM than males. A previous study suggested that young people are more likely to actively seek ways to improve their well-being and relieve disease symptoms [37]. The similar association between age and TCM use was also reported in previous studies with different scenarios $[13,14,16,31]$. It is thus reasonable that younger stroke patients had a higher tendency to use TCM and to represent higher TCM expenditure than older patients in this study.

Economic growth is a major determinant of physician supply and medical utilization [44]. TCM has become an increasingly popular form of medicine in Taiwan, particularly since the universal coverage for such services by the National Health Insurance. The increasing use of TCM is interacting with the growth in the number of TCM physicians in Taiwan [45]. Residents in urban areas have more access to TCM services than rural residents because more TCM physicians practice in cities than in rural areas $[14,16]$. Thus we found that high urbanization was a factor associated with TCM use. 
TABLE 3: Stratification analyses of sociodemographic factors and medical conditions on averaged frequency of visits and expenditure on traditional Chinese medicine among stroke patients $(N=4725)$.

\begin{tabular}{|c|c|c|c|c|}
\hline & \multicolumn{2}{|c|}{ TCM visits } & \multicolumn{2}{|c|}{ TCM expenditure } \\
\hline & Mean \pm SD & $P$ value & Mean $\pm S D$ & $P$ value \\
\hline \multicolumn{5}{|l|}{ Sex } \\
\hline Women & $8.1 \pm 10.7$ & 0.13 & $192 \pm 298$ & 0.02 \\
\hline Men & $8.6 \pm 11.0$ & & $212 \pm 314$ & \\
\hline \multicolumn{5}{|l|}{ Age, years } \\
\hline $20-29$ & $9.8 \pm 16.4$ & 0.0009 & $250 \pm 514$ & 0.0003 \\
\hline $30-59$ & $9.2 \pm 11.5$ & & $228 \pm 332$ & \\
\hline $60-69$ & $8.1 \pm 9.9$ & & $193 \pm 276$ & \\
\hline$\geq 70$ & $7.8 \pm 10.6$ & & $186 \pm 294$ & \\
\hline \multicolumn{5}{|l|}{ Occupation } \\
\hline White collar & $9.3 \pm 11.6$ & $<0.0001$ & $231 \pm 334$ & $<0.0001$ \\
\hline Blue collar & $7.6 \pm 10.0$ & & $179 \pm 272$ & \\
\hline Others & $8.7 \pm 11.8$ & & $218 \pm 344$ & \\
\hline \multicolumn{5}{|l|}{ Urbanization } \\
\hline Low & $7.3 \pm 10.2$ & 0.002 & $179 \pm 288$ & 0.0003 \\
\hline Moderate & $7.8 \pm 10.2$ & & $183 \pm 286$ & \\
\hline High & $8.9 \pm 11.3$ & & $218 \pm 321$ & \\
\hline \multicolumn{5}{|c|}{ Density of TCM physicians } \\
\hline Low & $7.5 \pm 9.7$ & 0.002 & $170 \pm 260$ & 0.0002 \\
\hline Moderate & $8.5 \pm 11.0$ & & $210 \pm 317$ & \\
\hline High & $9.1 \pm 11.4$ & & $219 \pm 323$ & \\
\hline \multicolumn{5}{|l|}{ Low income } \\
\hline No & $8.4 \pm 10.8$ & 0.49 & $203 \pm 307$ & 0.50 \\
\hline Yes & $10.3 \pm 15.0$ & & $254 \pm 420$ & \\
\hline \multicolumn{5}{|l|}{ Rehabilitation } \\
\hline No & $6.5 \pm 8.7$ & $<0.0001$ & $138 \pm 204$ & $<0.0001$ \\
\hline Yes & $10.8 \pm 12.8$ & & $288 \pm 387$ & \\
\hline \multicolumn{5}{|c|}{ Diabetes mellitus } \\
\hline No & $8.5 \pm 11.0$ & 0.29 & $205 \pm 308$ & 0.56 \\
\hline Yes & $8.2 \pm 10.5$ & & $200 \pm 306$ & \\
\hline \multicolumn{5}{|l|}{ Hypertension } \\
\hline No & $8.7 \pm 11.7$ & 0.16 & $216 \pm 343$ & 0.06 \\
\hline Yes & $8.2 \pm 10.4$ & & $197 \pm 286$ & \\
\hline \multicolumn{5}{|l|}{ Hyperlipidemia } \\
\hline No & $8.4 \pm 10.8$ & 0.58 & $203 \pm 307$ & 0.84 \\
\hline Yes & $8.6 \pm 11.1$ & & $206 \pm 312$ & \\
\hline \multicolumn{5}{|c|}{ Myocardial infarction } \\
\hline No & $8.4 \pm 10.9$ & 0.79 & $204 \pm 308$ & 0.83 \\
\hline Yes & $8.7 \pm 10.2$ & & $210 \pm 289$ & \\
\hline \multicolumn{5}{|l|}{ Renal dialysis } \\
\hline No & $8.4 \pm 10.9$ & 0.15 & $204 \pm 308$ & 0.31 \\
\hline Yes & $6.8 \pm 6.8$ & & $168 \pm 215$ & \\
\hline
\end{tabular}

SD: standard deviation; TCM: traditional Chinese medicine.

Among the stroke patients, hypertension, hyperlipidemia, diabetes, uremia, and myocardial infarction were common coexisting medical conditions considered as comorbidities in this study. We found that patients with comorbidities of hypertension or hyperlipidemia and patients without renal dialysis were more likely to use
TCM care. The beneficial effects of TCM treatment on hypertension and hyperlipidemia have been reported in previous studies $[46,47]$. Patients with end-stage renal disease receiving dialysis two or three times weekly might have less opportunity to use TCM. In contrast, stroke patients receiving TCM treatment have shorter hospitalization. Our 


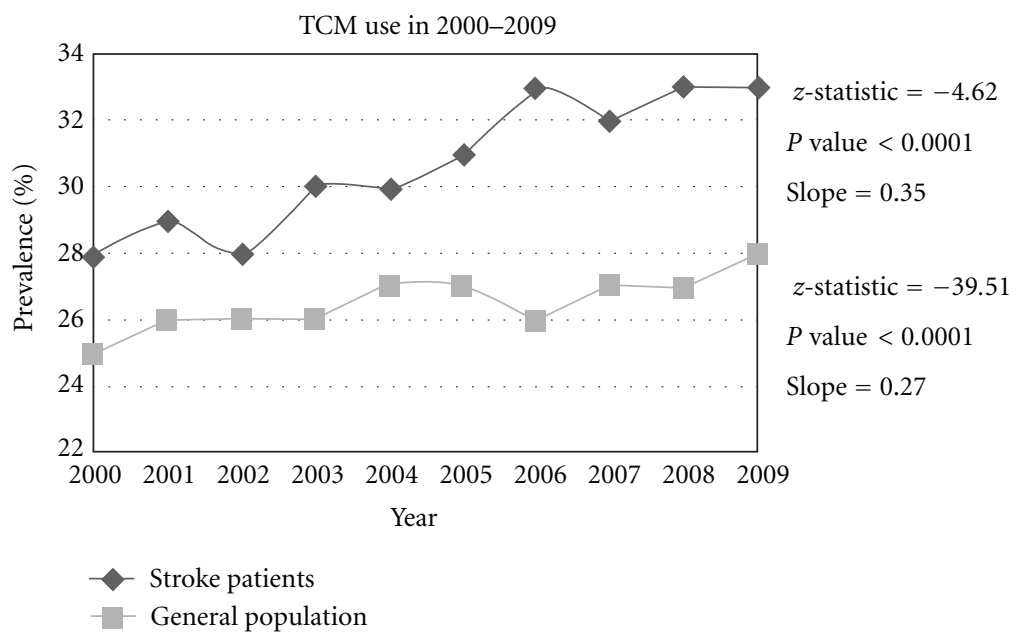

FIGURE 1: Use of traditional Chinese medicine services by patients with stroke and general population, 2000-2009 (use Cochran-Amitage Trend Test).

further analysis showed patients with hypertension had longer hospitalization (not shown in the tables). In addition, we found that stroke patients using TCM were more likely to use other types of physical treatment and rehabilitation simultaneously. Further analysis revealed that these patients faced lower risk of recurrent stroke (not shown in tables). The frequency of TCM visits and related expenditure were higher in stroke patients receiving physical treatment and rehabilitation. Our previous study [8] discussed how stroke patients who accessed regular rehabilitation services may have better knowledge, attitudes, and practices regarding disease prevention and how this population may embrace pluralistic attitudes about health care [13]. Healthy lifestyles were also a characteristic of TCM users $[14,16]$.

While previous studies provided by self-reported information collected through interviews, the current study used the Taiwan National Health Insurance claims data that may avoid recall bias. In addition, our study used multivariate logistic regression analysis to study factors associated with TCM use in stroke patients after adjustment for covariates. To the best of our knowledge, this study is the first population-based study showing the utilization of TCM and its associated factors in stroke patients.

This study has some limitations. First, we used retrospective medical claims data from health insurance that lacked detailed patient information on lifestyle as well as physical, psychiatric, and laboratory examinations. We were unable to differentiate whether these factors were causally related with TCM use. Second, our study used ICD-9-CM codes claimed by physicians for the diagnosis of stroke without clarifying the severity of disease. We supposed that severe stroke patients may have had less opportunity to use TCM because of their activity limitations and longer hospital stays. Third, information on folk therapy, which has been reported as a predictor for TCM use, was not available in the National Health Insurance Research Database [13, 14, 16]. Finally, this study was based on cross-sectional analyses of TCM use in stroke patients. The beneficial effects of TCM in stroke patients require further cohort studies.

In conclusion, the application of TCM in stroke patients is well accepted and increasing in Taiwan. Stroke patients use TCM more often than people without stroke, and this is associated with sociodemographic factors and clinical characteristics. This study may provide some clinical implications of CAM in these populations that are useful for health professionals worldwide.

\section{Acknowledgments}

This study is based (in part) on data from the National Health Insurance Research Database provided by the National Health Research Institutes. The interpretation and conclusions contained herein do not represent those of the National Health Research Institutes. This study was supported in part by a Grant from the Committee on Chinese Medicine and Pharmacy, Department of Health, Taiwan (Grant no. CCMP98-RD-038), the China Medical University Hospital (Grant no. 1MS1), the Taiwan Department of Health Clinical Trial and Research Center for Excellence (Grant no. DOH101-TD-B-111-004), and the Taiwan Department of Health Cancer Research Center of Excellence (Grant no. DOH101-TD-C-111-005). The funders had no role in study design, data collection and analysis, decision to publish, or preparation of the paper C.-C. Liao and T.-L. Chen contributed equally in the paper.

\section{References}

[1] S. Lee, A. C. E. Shafe, and M. R. Cowie, "UK stroke incidence, mortality and cardiovascular risk management 1999-2008: time-trend analysis from the General Practice Research Database," British Medical Journal Open, vol. 1, no. 2, Article ID e000269, 2011.

[2] K. Strong, C. Mathers, and R. Bonita, "Preventing stroke: saving lives around the world," Lancet Neurology, vol. 6, no. 2, pp. 182-187, 2007. 
[3] M. J. O’Donnell, X. Denis, L. Liu et al., "Risk factors for ischaemic and intracerebral haemorrhagic stroke in 22 countries (the INTERSTROKE study): a case-control study," The Lancet, vol. 376, no. 9735, pp. 112-123, 2010.

[4] C.-C. Liao, T.-C. Su, F.-C. Sung, W.-H. Chou, and T.-L. Chen, "Does hepatitis $\mathrm{C}$ virus infection increase risk for stroke? A population-based cohort study," PLoS ONE, vol. 7, no. 2, Article ID e31527, 2012.

[5] I. K. Wang, S. N. Chang, C. C. Liao et al., "Hypertensive disorders in pregnancy and preterm delivery and subsequent stroke in Asian women: a retrospective cohort study," Stroke, vol. 42, no. 3, pp. 716-721, 2011.

[6] S. Kumar, M. H. Selim, and L. R. Caplan, "Medical complications after stroke," The Lancet Neurology, vol. 9, no. 1, pp. 105-118, 2010.

[7] P. Langhorne, D. J. Stott, L. Robertson et al., "Medical complications after stroke: a multicenter study," Stroke, vol. 31, no. 6, pp. 1223-1229, 2000.

[8] Y.-C. Chou, C.-C. Liao, L.-T. Su, P.-Y. Yang, and F.-C. Sung, "Stroke rehabilitation is associated with a reduction in dementia risk: a population-based retrospective cohort study," Journal of Rehabilitation Medicine, vol. 44, no. 4, pp. 319-324, 2012.

[9] D. M. Eisenberg, R. C. Kessler, C. Foster, F. E. Norlock, D. R. Calkins, and T. L. Delbanco, "Unconventional medicine in the United States-prevalence, costs, and patterns of use," New England Journal of Medicine, vol. 328, no. 4, pp. 246-252, 1993.

[10] D. M. Eisenberg, R. B. Davis, S. L. Ettner et al., "Trends in alternative medicine use in the United States, 1990-1997: results of a follow-up national survey," Journal of the American Medical Association, vol. 280, no. 18, pp. 1569-1575, 1998.

[11] R. C. Kessler, R. B. Davis, D. F. Foster et al., "Long-term trends in the use of complementary and alternative medical therapies in the United States," Annals of Internal Medicine, vol. 135, no. 4, pp. 262-268, 2001.

[12] M. H. Cohen and K. J. Kemper, "Complementary therapies in pediatrics: a legal perspective," Pediatrics, vol. 115, no. 3, pp. 774-780, 2005.

[13] C. C. Shih, J. G. Lin, C. C. Liao, and Y. C. Su, "The utilization of traditional Chinese medicine and associated factors in Taiwan in 2002," Chinese Medical Journal, vol. 122, no. 13, pp. 15441548, 2009.

[14] C. C. Shih, Y. C. Su, C. C. Liao, and J. G. Lin, "Patterns of medical pluralism among adults: results from the 2001 National Health Interview Survey in Taiwan," BMC Health Services Research, vol. 10, article 191, 2010.

[15] C.-C. Shih, C.-C. Liao, Y.-C. Su, T. F. Yeh, and J.-G. Lin, “The association between socioeconomic status and traditional chinese medicine use among children in Taiwan," BMC Health Services Research, vol. 12, no. 1, article 27, 2012.

[16] C.-C. Shih, C.-C. Liao, Y.-C. Su, C.-C. Tsai, and J.-G. Lin, "Gender differences in traditional chinese medicine use among adults in Taiwan," PLoS ONE, vol. 7, no. 4, article e32540, 2012.

[17] T. P. Ng, C. H. Tan, and E. H. Kua, "The use of Chinese herbal medicines and their correlates in Chinese older adults: the Singapore Chinese longitudinal aging study," Age and Ageing, vol. 33, no. 2, pp. 135-142, 2004.

[18] V. C. Chung, C. H. Lau, E. K. Yeoh, and S. M. Griffiths, "Age, chronic non-communicable disease and choice of traditional Chinese and western medicine outpatient services in a Chinese population," BMC Health Services Research, vol. 9, article 207, 2009.
[19] V. Chung, E. Wong, J. Woo, S. V. Lo, and S. Griffiths, "Use of traditional chinese medicine in the Hong Kong special administrative region of China," Journal of Alternative and Complementary Medicine, vol. 13, no. 3, pp. 361-367, 2007.

[20] H. Chang, Y. D. Kwon, and S. S. Yoon, "Use of acupuncture therapy as a supplement to conventional medical treatments for acute ischaemic stroke patients in an academic medical centre in Korea," Complementary Therapies in Medicine, vol. 19, no. 5, pp. 256-263, 2011.

[21] L. C. Chang, N. Huang, Y. J. Chou, C. H. Lee, F. Y. Kao, and Y. T. Huang, "Utilization patterns of Chinese medicine and Western medicine under the National Health Insurance Program in Taiwan, a population-based study from 1997 to 2003," BMC Health Services Research, vol. 8, article 170, 2008.

[22] P. M. Wayne, D. E. Krebs, E. A. Macklin et al., "Acupuncture for upper-extremity rehabilitation in chronic stroke: a randomized sham-controlled study," Archives of Physical Medicine and Rehabilitation, vol. 86, no. 12, pp. 2248-2255, 2005.

[23] M. Mukherjee, L. K. McPeak, J. B. Redford, C. Sun, and W. Liu, "The effect of electro-acupuncture on spasticity of the wrist joint in chronic stroke survivors," Archives of Physical Medicine and Rehabilitation, vol. 88, no. 2, pp. 159-166, 2007.

[24] J. G. Zhao, C. H. Cao, C. Z. Liu et al., "Effect of acupuncture treatment on spastic states of stroke patients," Journal of the Neurological Sciences, vol. 276, no. 1-2, pp. 143-147, 2009.

[25] J. Park, A. R. White, M. A. James et al., "Acupuncture for subacute stroke rehabilitation: a sham-controlled, subjectand assessor-blind, randomized trial," Archives of Internal Medicine, vol. 165, no. 17, pp. 2026-2031, 2005.

[26] Y. C. Wei, M. F. Sun, K. C. Chang et al., "Pilot Scheme of health policy in stroke adjuvant acupuncture therapy for acute and subacute ischemic stroke in Taiwan," Evidence-based Complementary and Alternative Medicine, vol. 2011, Article ID 689813, 9 pages, 2011.

[27] J.-G. Lin, Y.-Y. Chan, and Y.-H. Chen, "Acupuncture for the treatment of opiate addiction," Evidence-based Complementary and Alternative Medicine, vol. 2012, Article ID 739045, 2012.

[28] D. Lee, H. Xu, J. G. Lin, K. Watson, R. S. Wu, and K. B. Chen, "Needle-free electroacupuncture for postoperative pain management," Evidence-Based Complementary and Alternative Medicine, vol. 2011, Article ID 696754, 7 pages, 2011.

[29] C. L. Cheng, Y. H. Y. Kao, S. J. Lin, C. H. Lee, and M. L. Lai, "Validation of the national health insurance research database with ischemic stroke cases in Taiwan," Pharmacoepidemiology and Drug Safety, vol. 20, no. 3, pp. 236-242, 2011.

[30] V. C. H. Chung, S. Hillier, C. H. Lau, S. Y. S. Wong, E. K. Yeoh, and S. M. Griffiths, "Referral to and attitude towards traditional Chinese medicine amongst western medical doctors in postcolonial Hong Kong," Social Science and Medicine, vol. 72, no. 2, pp. 247-255, 2011.

[31] S. F. Shih, C. Y. Lew-Ting, H. Y. Chang, and K. N. Kuo, "Insurance covered and non-covered complementary and alternative medicine utilisation among adults in Taiwan," Social Science and Medicine, vol. 67, no. 7, pp. 1183-1189, 2008.

[32] V. W. S. Wong, M. Y. Law, A. Y. Hui et al., "A hospital clinicbased survey on traditional Chinese medicine usage among chronic hepatitis B patients," Complementary Therapies in Medicine, vol. 13, no. 3, pp. 175-182, 2005.

[33] C. H. Loh, "Use of traditional Chinese medicine in Singapore children: perceptions of parents and paediatricians," Singapore Medical Journal, vol. 50, no. 12, pp. 1162-1168, 2009. 
[34] M. T. Chao, K. M. Tippens, and E. Connelly, "Utilization of group-based, community acupuncture clinics: a comparative study with a nationally representative sample of acupuncture users," Journal of Alternative and Complementary Medicine, vol. 18, no. 6, pp. 561-566, 2012.

[35] M. Bonafede, A. Dick, K. Noyes, J. D. Klein, and T. Brown, "The effect of acupuncture utilization on healthcare utilization," Medical Care, vol. 46, no. 1, pp. 41-48, 2008.

[36] B. Wu, M. Liu, H. Liu et al., "Meta-analysis of traditional Chinese patent medicine for ischemic stroke," Stroke, vol. 38, no. 6, pp. 1973-1979, 2007.

[37] P. Wu, E. Mills, D. Moher, and D. Seely, "Acupuncture in poststroke rehabilitation: a systematic review and metaanalysis of randomized trials," Stroke, vol. 41, no. 4, pp. e171e179, 2010.

[38] F. K. H. Sze, E. Wong, K. H. Kevin, J. Lau, and J. Woo, “Does acupuncture improve motor recovery after stroke? A metaanalysis of randomized controlled trials," Stroke, vol. 33, no. 11, pp. 2604-2619, 2002.

[39] G. Gosman-Hedström, L. Claesson, U. Klingenstierna et al., "Effects of acupuncture treatment on daily life activities and quality of life: a controlled, prospective, and randomized study of acute stroke patients," Stroke, vol. 29, no. 10, pp. 2100-2108, 1998.

[40] B. B. Johansson, E. Haker, M. Von Arbin et al., "Acupuncture and transcutaneous nerve stimulation in stroke rehabilitation: a randomized, controlled trial," Stroke, vol. 32, no. 3, pp. 707713, 2001.

[41] J. C. Kong, M. S. Lee, B. C. Shin, Y. S. Song, and E. Ernst, "Acupuncture for functional recovery after stroke: a systematic review of sham-controlled randomized clinical trials," Canadian Medical Association Journal, vol. 182, no. 16, pp. 17231729, 2010.

[42] M. Daly, C. J. Tai, C. Y. Deng, and L. Y. Chien, "Factors associated with utilization of traditional Chinese medicine by white collar foreign workers living in Taiwan," BMC Health Services Research, vol. 9, no. 1, article 10, 2009.

[43] L. L. Yeh, J. Y. Liu, K. S. Lin et al., "A randomised placebocontrolled trial of a traditional Chinese herbal formula in the treatment of primary dysmenorrhoea," PloS One, vol. 2, no. 8, article e719, 2007.

[44] R. A. Cooper, T. E. Getzen, and P. Laud, "Economic expansion is a major determinant of physician supply and utilization," Health Services Research, vol. 38, no. 2, pp. 675-696, 2003.

[45] W. C. Tsai and P. T. Kung, "Relationship between Chinese medical utilization and growth of physicians," Taiwan Journal of Public Health, vol. 20, no. 6, pp. 463-474, 2001.

[46] F. A. Flachskampf, J. Gallasch, O. Gefeller et al., "Randomized trial of acupuncture to lower blood pressure," Circulation, vol. 115, no. 24, pp. 3121-3129, 2007.

[47] M. T. Cabioğlu and N. Ergene, "Electroacupuncture therapy for weight loss reduces serum total cholesterol, triglycerides, and ldl cholesterol levels in obese women," American Journal of Chinese Medicine, vol. 33, no. 4, pp. 525-533, 2005. 


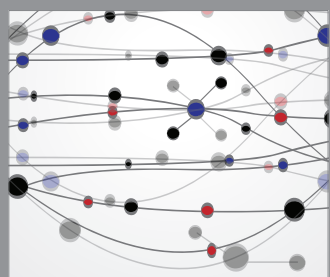

The Scientific World Journal
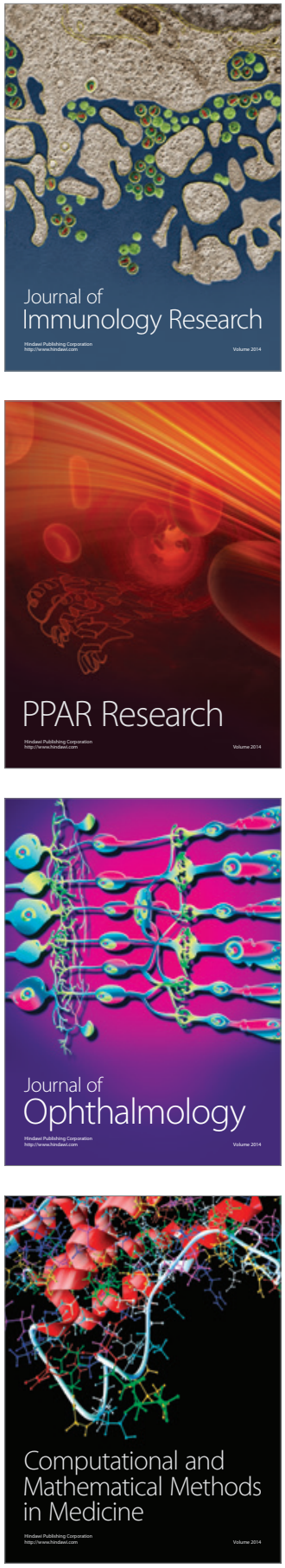

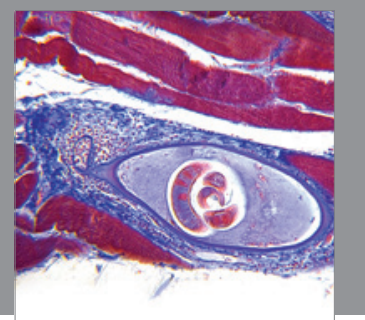

Gastroenterology

Research and Practice
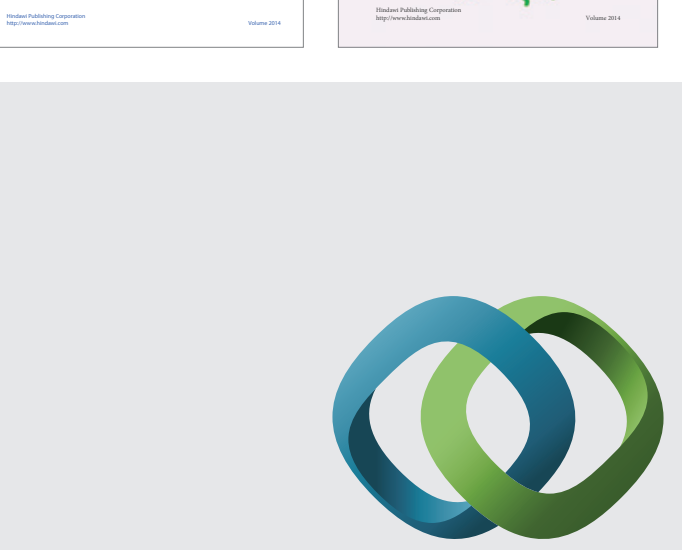

\section{Hindawi}

Submit your manuscripts at

http://www.hindawi.com
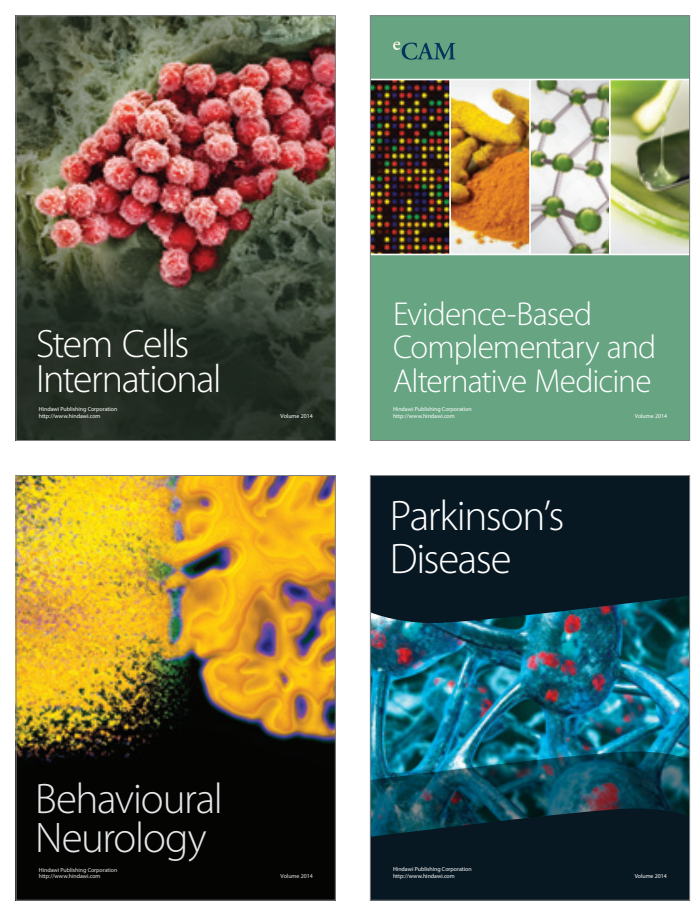

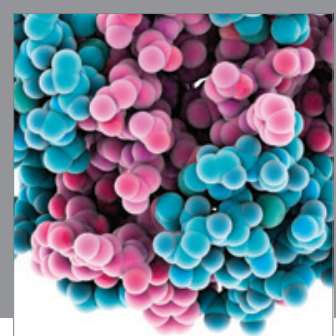

Journal of
Diabetes Research

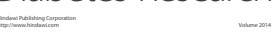

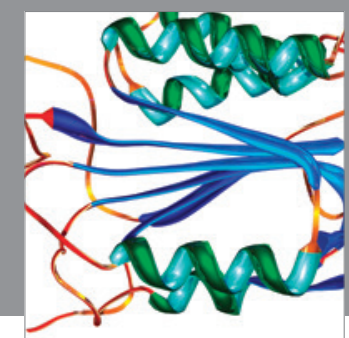

Disease Markers
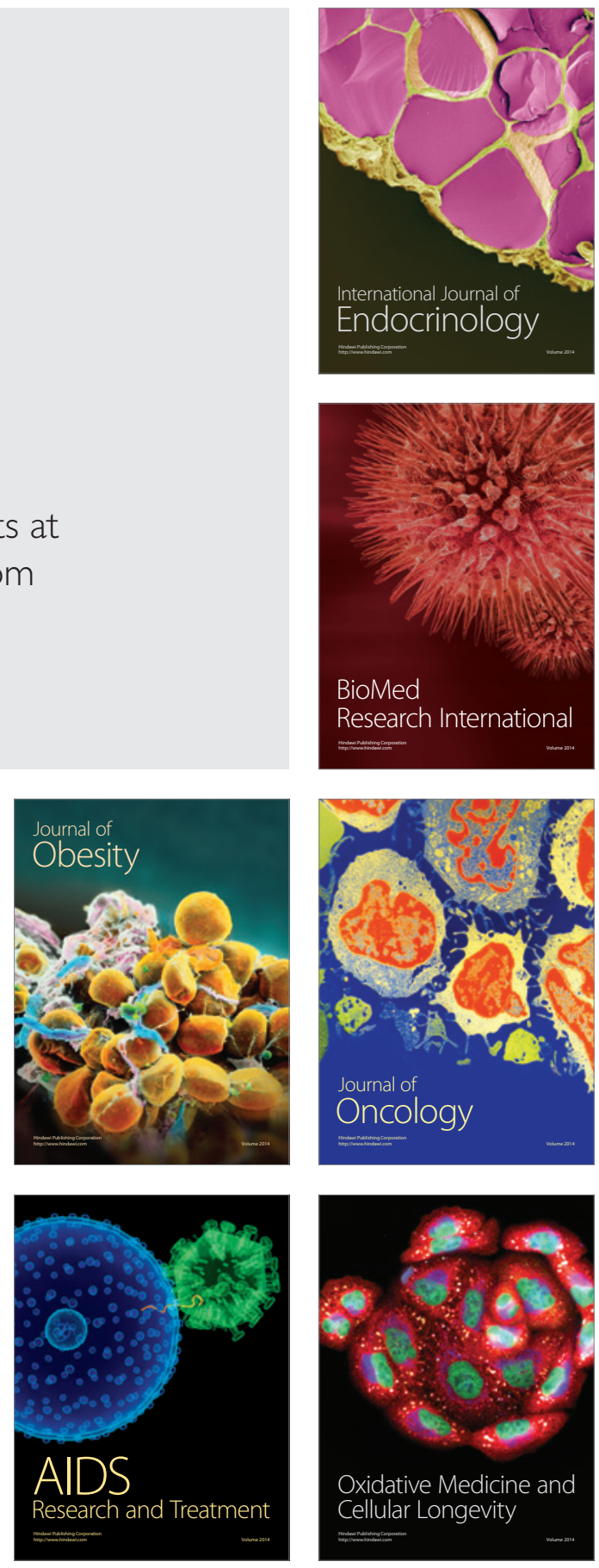